\title{
Higher susceptibility of NOG mice to xenotransplanted tumors
}

\author{
Kazuhiko Machida', Hiroshi Suemizu², Kenji Kawai³ ${ }^{3}$ Tsuyoshi Ishikawa4, Rumi Sawada4, \\ Yasuyuki Ohnishi ${ }^{2}$ and Toshie Tsuchiya ${ }^{4}$ \\ ${ }^{1}$ Testing Services Department, ${ }^{2}$ Biomedical Research Department, ${ }^{3}$ Pathology Research Department, Central Institute \\ for Experimental Animals, 1430 Nogawa, Miyamae, Kawasaki, Kanagawa 216-0001, Japan \\ ${ }^{4}$ Division of Medical Devices, National Institute of Health Sciences, 1-18-1 Kimiyoga, Setagaya, Tokyo 158-8501, \\ Japan
}

(Received October 17, 2008; Accepted November 14, 2008)

\begin{abstract}
The purpose of tumorigenicity testing, as applied not only to cell substrates used for viral vaccine manufacture but also stem cells used for cell-based therapy, is to discriminate between cells that have the capacity to form tumors and cells that do not. Therefore, tumorigenicity testing is essential in assessing the safety of these biological materials. Recently developed NOD/Shi-scid IL2Rg null (NOG) mice have been shown to be superior to NOD/Shi-scid (SCID) mice for xenotransplantation of both normal and cancerous cells. To select a suitable mouse strain as a xenogenic host for tumorigenicity testing, we compared the susceptibility of NOG (T, B, and NK cell-defective), SCID (T and B cell-defective), and the traditionally used nude ( $\mathrm{T}$ cell-defective) mice to tumor formation from xenotransplanted HeLa S3 cells. When $10^{4} \mathrm{HeLa} S 3$ cells were subcutaneously inoculated into the flanks of these mice, the tumor incidence on day 22 was 10/10 (100\%) in NOG, 2/10 (20\%) in SCID, and 0/10 (0\%) in nude mice. The subcutaneous tumors formed reproducibly and semiquantitatively in a dose-dependent manner. Unexpectedly, half of the NOG mice (5/10) that had been inoculated with a mere $10^{1} \mathrm{HeLa}$ S3 cells formed progressively growing subcutaneous tumors on day 78 . We confirmed that the engrafted tumors originated from inoculated HeLa S3 cells by immunohistochemical staining with anti-HLA antibodies. These data suggest that NOG mice may be the best choice as a suitable strain for testing tumorigenicity.
\end{abstract}

Key words: HeLa S3, NOD/Shi-scid IL2Rgnull (NOG), Tumorigenicity testing, Xenograft

\section{INTRODUCTION}

One of the greatest contributions of the cultured cell to health care is the production of biologicals involving viral vaccines (Balducci et al., 1962; Robinson et al., 1966) and humoral factors (Delzer et al., 1985; Sambrook et al., 1986). Recently developed cell culture technology provides us with a new application known as "stem cell therapy" in the field of regenerative medicine (Badayan and Cudkowicz, 2008; Dalbello-Haas et al., 2008). Stem cellbased therapy has received attention as a possible alternative to organ transplantation, owing to the ability of stem cells to repopulate and differentiate at the engrafted site. In particular, induced pluripotent stem (iPS) cells (Okita et al., 2007; Takahashi et al., 2007) would be the best source of patient-specific cell therapy, and thus enable us to autologously transplant without an immune rejec- tion because of immunological incompatibility between patient and donor. In contrast to cell substrates for producing biologicals, in cell-based therapies, the therapeutic cells must be transplanted into the patient directly. The anticipated benefit of patient-specific cell therapies has always been tempered by inherent worries concerning the undesirable growth of contaminated undifferentiated stem cells in the recipient. Although many factors (e.g., cell migration, differentiation, phenotype expression, tumorigenicity) have been involved, the transplantable therapeutic cell has always been considered a safety risk. The purpose of tumorigenicity testing, as applied not only to cell substrates used for viral vaccine manufacture but also differentiated stem cells (e.g., derived from embryonic, mesenchymal, hematopoietic stem, and iPS) used for cellbased therapy, is to discriminate between cells that have the capacity to form tumors and cells that do not.

Correspondence: Hiroshi Suemizu (E-mail: suemizu@ciea.or.jp) 
Recently, we developed NOD/Shi-scid IL2Rgnull (NOG) mice by crossing IL-2 receptor gamma chain-deficient (IL2Rgnull) mice (Ohbo et al., 1996) with NOD/Shiscid mice (SCID) (Koyanagi et al., 1997). NOG mice lack $\mathrm{T}$ and $\mathrm{B}$ lymphocytes and natural killer (NK) cells, and demonstrate impaired dendritic cell function (Ito et al., 2002, 2008; Yahata et al., 2002). Because of their severe immunodeficient state, NOG mice have been used as an in vivo model to study human cells and tissues (Ito et al., 2002; Yahata et al., 2002; Matsuura-Sawada et al., 2005; Masuda et al., 2007; Suemizu et al., 2008). NOG mice also showed superiority in cancer xenotransplantation systems compared to SCID (Nakamura and Suemizu, 2008). To select a suitable mouse strain as a xenogenic host for testing tumorigenicity, we compared the susceptibility of NOG (T, B, and NK cell-defective), SCID (T and $\mathrm{B}$ cell-defective), and the traditionally used nude (T celldefective) mice for tumor formation from xenotransplanted HeLa S3 cells.

\section{MATERIALS AND METHODS}

The protocol of the present study was reviewed beforehand and approved by the Animal Ethics Committee of the Central Institute for Experimental Animals (CIEA, Kanagawa, Japan), and all animal experiments were performed according to the Ethical Guidelines for Animal Experimentation from the CIEA.

\section{Cells}

HeLa S3 (human cervical cancer cell line) cells were obtained from the Health Science Research Resources Bank (HSRRB, Osaka, Japan). The cells were maintained in F-12 (HAM) (Gibco, Carlsbad, CA, USA) supplemented with 10\% fetal bovine serum (FBS) (HyClone, Logan, UT, USA), incubated in a humidified $\left(37^{\circ} \mathrm{C}, 5 \% \mathrm{CO}_{2}\right)$ incubator, and passaged on reaching $80 \%$ confluence.

\section{Detection of the tumorigenic cells in vivo}

We used BALB/cA nu/nu (nude; Clea Japan Inc., Tokyo, Japan) and SCID (Clea Japan Inc.), and NOG mice aged 6-8 weeks. For direct comparison of susceptibility to cancer cell engraftment, various concentrations ( $10^{1}$ to $10^{6}$ cells/head) of HeLa S3 cells suspended in 0.1 $\mathrm{ml}$ of serum-free medium were subcutaneously inoculated into ten mice ( 5 males and 5 females) of each strain. The mice were surveyed daily and tumors were measured with calipers. The tumor volume (TV) was calculated using the formula $\mathrm{TV}=1 / 2 \times \mathrm{A} \times \mathrm{B}^{2}$ (A: length $(\mathrm{mm})$; $B$ : width $(\mathrm{mm})$ ). The criteria for successive engraftment were as follows: progressive nodule growth at the site of injection and TV values exceeding $10 \mathrm{~mm}^{3}$.

\section{Histology and immunohistochemistry}

The engrafted tumors were fixed with $4 \%$ (v/v) phosphate-buffered formalin, and paraffin-embedded sections were stained using hematoxylin and eosin (H\&E). Some sections were autoclaved for $10 \mathrm{~min}$ in target retrieval solution ( $0.1 \mathrm{M}$ citrate buffer, $\mathrm{pH} 6.0 ; 1 \mathrm{mM}$ EDTA, $\mathrm{pH} 9.0$ ) and then placed at room temperature for 20 min. Monoclonal mouse anti-HLA class I-A, B, C (clone EMR8-5; Hokudo, Sapporo, Japan), mouse antihuman CK8/18 (clone 5D3; Novocastra Laboratories, Newcastle, UK), and mouse monoclonal antihuman Ki67 antigen (clone MIB-1; Dako A/S, Glostrup, Denmark) were the primary antibodies used. The antibodies for mouse Ig were visualized using amino acid polymer/peroxidase complex-labeled antibodies (Histofine Simple Stain Mouse MAX PO (M); Nichirei Bioscience, Tokyo, Japan) and diaminobenzidine (DAB) (Dojindo Laboratories, Kumamoto, Japan) substrate $(0.2 \mathrm{mg} / \mathrm{ml}$ 3,3'-diaminobenzidine tetrahydrochloride, $0.05 \mathrm{M}$ Tris- $\mathrm{HCl}(\mathrm{pH}$ 7.6), and $0.005 \% \mathrm{H}_{2} \mathrm{O}_{2}$ ). Sections were counterstained with hematoxylin.

\section{Statistical analyses}

The differences in incidence of each engraftment were tested by Fisher's direct probability method with $\mathrm{p}<0.05$ as the cutoff for significance. All statistical analyses were performed using Prism 5 software (GraphPad Software, La Jolla, CA, USA).

\section{RESULTS AND DISCUSSION}

In previous reports, we demonstrated a high rate of liver metastasis in NOG mice inoculated with small numbers of pancreatic cancer cells (as few as 100 cells) and higher levels of liver metastasis in NOG mice than in SCID mice (Suemizu et al., 2007). Therefore, NOG mice are expected to be better subjects for testing tumorigenicity in assessing the safety of cell substrates and therapeutic cells. The purpose of this study was to quantify the advantage of NOG mice over SCID and nude mice in terms of transplantability of human tumor cells. HeLa S3 was examined for its ability to engraft in the subcutaneous spaces of these mice (Table 1). No statistically significant differences were found in the tumorigenic incidence between male and female mice in all strains. Therefore, tumorigenic incidence was directly compared between each strain. The athymic nude mice, traditional standards for tumorigenicity testing, showed no tumor formation when HeLa S3 cells were seeded at a density 
Higher susceptibility of NOG mice to xenotransplanted tumors

Table 1. Comparative growth of HeLa S3 cells among BALB/cA nu/nu, SCID, and NOG mice

\begin{tabular}{|c|c|c|c|c|}
\hline \multirow{2}{*}{$\begin{array}{l}\text { Cell dose } \\
\text { (cells/head) }\end{array}$} & \multirow[t]{2}{*}{ Sex } & \multicolumn{3}{|c|}{ Number of mice with tumors ( $\%$ engraftment $)^{a}$} \\
\hline & & $\mathrm{BALB} / \mathrm{cA} n u / n u$ & SCID & NOG \\
\hline \multirow[t]{3}{*}{$1 \times 10^{2}$} & Male & NT & $0 / 5(0 \%)$ & $3 / 5(60 \%)$ \\
\hline & Female & NT & $0 / 5(0 \%)$ & $3 / 5(60 \%)$ \\
\hline & Total & NT & $0 / 10(0 \%)$ & $6 / 10(60 \%) *$ \\
\hline \multirow[t]{3}{*}{$1 \times 10^{3}$} & Male & $0 / 5(0 \%)$ & $0 / 5(0 \%)$ & $3 / 5(60 \%)$ \\
\hline & Female & $0 / 5(0 \%)$ & $0 / 5(0 \%)$ & $3 / 5(60 \%)$ \\
\hline & Total & $0 / 10(0 \%)$ & $0 / 10(0 \%)$ & $6 / 10(60 \%)^{\#}$ \\
\hline \multirow[t]{3}{*}{$1 \times 10^{4}$} & Male & $0 / 5(0 \%)$ & $2 / 5(40 \%)$ & $5 / 5(100 \%) * *$ \\
\hline & Female & $0 / 5(0 \%)$ & $0 / 5(0 \%)$ & $5 / 5(100 \%))^{\#}$ \\
\hline & Total & $0 / 10(0 \%)$ & $2 / 10(20 \%)$ & $10 / 10(100 \%)$ \\
\hline \multirow[t]{3}{*}{$1 \times 10^{5}$} & Male & $5 / 5(100 \%)$ & $5 / 5(100 \%)$ & NT \\
\hline & Female & $3 / 5(60 \%)$ & $4 / 5(80 \%)$ & NT \\
\hline & Total & $8 / 10(80 \%)$ & $9 / 10(90 \%)$ & NT \\
\hline
\end{tabular}

a Engraftment was evaluated 22 days after inoculation by $1 \times 10^{3}, 10^{4}$, and $10^{5}$ cancer cells, and 43 days after inoculation by $1 \times 10^{2}$ cancer cells. Fisher's exact test was performed in statistical analysis. $* \mathrm{P}<0.05$ compared to the SCID strain. $* * \mathrm{P}<0.01$ compared to the BALB/cA $n u / n u$ strain. ${ }^{~} \mathrm{P}<0.05$ compared to the BALB/cA $n u / n u$ and SCID strain. ${ }^{\#} \mathrm{P}<0.01$ compared to the BALB/cA $n u /$ $n u$ and SCID strain. NT: not tested.

of up to $10^{5}$ cells. The SCID mice developed tumors with a lower cell inoculation dosage $\left(10^{4}\right.$ cells $)$ compared to nude mice. This result supports the report stating that the implantation rate of human xenografts in subcutaneous tissue is significantly higher in SCID mice than in nude mice (Taghian et al., 1993). SCID mice inoculated with $10^{4} \mathrm{HeLa} \mathrm{S} 3$ cells formed tumors within 22 days postinoculation, but at a rate of only $20 \%(2 / 10)$. In contrast to nude and SCID mice, all NOG mice $(10 / 10 ; 100 \%)$ inoculated with $10^{4} \mathrm{HeLa} \mathrm{S} 3$ cells formed tumors within 22 days. Furthermore, $60 \%(6 / 10)$ of the NOG mice formed subcutaneous solid tumors within 22 days of inoculation with only $10^{3} \mathrm{HeLa} \mathrm{S3}$ cells, and all NOG mice (10/10; $100 \%$ ) formed tumors within 43 days (data not shown). On the other hand, no tumor formation was observed in
SCID mice within 22 days of inoculation with $10^{3} \mathrm{HeLa}$ S3 cells, while 60\% (6/10) formed subcutaneous solid tumors within 43 days (data not shown). Earlier, we demonstrated that just $10^{2}$ AsPC-1, MIA PaCa-2, and PANC-1 cells (human pancreatic cancer cell lines) were needed for engraftment in NOG mice livers by intrasplenic inoculation within 56 days (Suemizu et al., 2007). In this study, we examined the tumor-forming potential of subcutaneous tissue in NOG mice when inoculated with $10^{2} \mathrm{HeLa}$ $\mathrm{S} 3$ cells. Although the inoculation site differed from that of previous studies, the NOG mice showed a high engraftment rate $(6 / 10 ; 60 \%)$ within 43 days of inoculation with $10^{2} \mathrm{HeLa} \mathrm{S} 3$ cells, but not within 22 days $(0 / 10 ; 0 \%$, data not shown). These results demonstrate that the NOG mouse model is more sensitive for detecting tumorigenic- 
ity of HeLa S3 cells, and is faster than traditional animal models using nude or SCID mice.

In cell-based therapies, huge numbers of cells are transplanted at the site of the lesion; most problematic among the risks is their potential neoplastic transformation or contamination of transformable undifferentiated stem cells. Therefore, susceptibility to xenotransplanted tumor cells has to be as high as possible. We examined the transplantability of NOG mice in response to a much lower $\left(10^{1}\right)$ dose of HeLa S3 cells. Unexpectedly, half of the NOG mice $(5 / 10)$ inoculated with this dosage showed tumor formation in their subcutaneous spaces at 78 days after transplantation. Fig. 1 shows the growth curve of engrafted HeLa S3 cells in NOG mice. The tumors grew progressively and formed a large spheroid mass, although it was localized at the inoculation site and did not invade surrounding areas. A necrotic core was usually observed in advanced tumors (Fig. 2A). Almost all tumor cells, except for the necrotic tumor tissue, were positive for the cell-cycle-regulated nuclear protein, Ki67 antigen, which is widely used as an operational marker of proliferation (Fig. 2B). To determine the origin of the engrafted tumors in the NOG mice, serial sections from formalin-fixed, paraffin-embedded tumors were treated with an anti-HLA monoclonal antibody using the immunoperoxidase staining method. The immunohistochemical reactivity of the anti-HLA monoclonal antibody with the tissue sections demonstrated that the engrafted tumors originated from a human source (Fig. 2C). HeLa S3 cells are immortalized epithelial cells obtained from a human cervical carcinoma (Masters, 2002) and retain the original characteristics of those cells. Moll et al. (1982) reported that the antibodies for cytokeratin component 18 strongly stained a variety of tumors of epithelial origin. Therefore, we checked the expression of cytokeratin 8 and 18 intermediate filament proteins (CK8/18) as an epithelial marker. Fig. 2D illustrates the immunohistochemical reactivity of the antiCK8/18 monoclonal antibody with a tissue section from subcutaneous tumors. Tumor cells were strongly stained, but cells in the stroma were negative. These results demonstrate that the engrafted tumors were progressively growing, originated from human HeLa S3 cells, and were not spontaneously generated by mouse cells.

Manufacturers and regulatory agencies have been developing scientifically based guidelines for the use of cell substrates for biologicals (2006, Center for Biologics Evaluation and Research, Food and Drug Administration (CBER/FDA)). The use of an animal model known to be susceptible to tumor formation by tumorigenic cells has been recommended. Due to their immunodeficiency (T-cell deficient), athymic nude mice have been the animals most commonly used for tumorigenicity testing. In this study, we demonstrated that NOG mice are more susceptible to tumor formation than the nude mice traditionally used. This suggests that NOG mice may be the best choice when identification of a weakly tumorigenic phenotype or a small contamination of transformable undifferentiated cells is important.

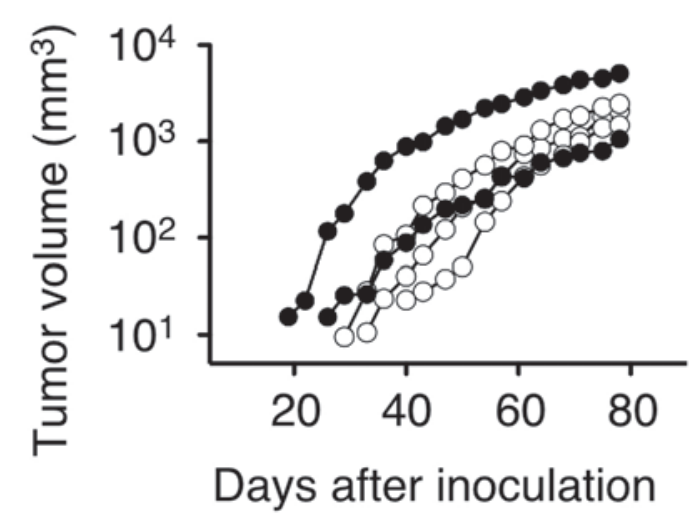

Fig. 1. Growth curve of subcutaneous tumors in NOG mice formed by inoculation with $10^{1} \mathrm{HeLa} \mathrm{S} 3$ cells. Closed and open circles indicate male $(\mathrm{n}=2)$ and female $(\mathrm{n}=3)$ mice, respectively.
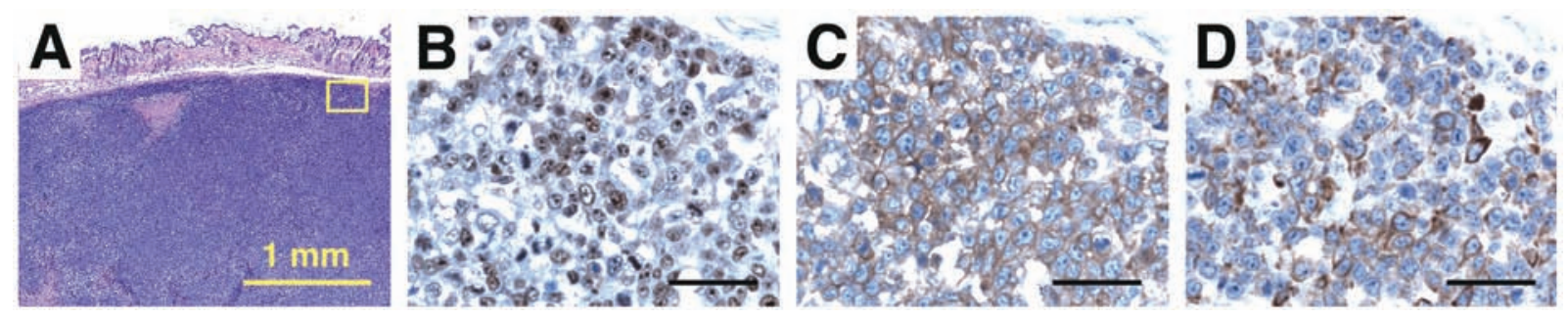

Fig. 2. Histology and immunohistochemistry of subcutaneous tumors in NOG mice formed by inoculation with $10^{1} \mathrm{HeLa}$ S3 cells. Serial sections were stained with H\&E (A), Ki67 (B), HLA (C) and h-CK8/18 (D). B to D shows the boxed area in A at higher magnification. Scale bar, $50 \mu \mathrm{m}$. 
Higher susceptibility of NOG mice to xenotransplanted tumors

\section{ACKNOWLEDGMENTS}

We thank M. Kuronuma, Y. Ando, and T. Ogura for their excellent technical assistance with animal experiments. This work was partially supported by Health and Labour Science Research Grants on Regenerative Medicine from the Japanese Ministry of Health, Labour and Welfare to TT, and the Global Center of Excellence Program, "Education and Research Center for Stem Cell Medicine" (leader: H. Okano, Keio University).

\section{REFERENCES}

Badayan, I. and Cudkowicz, M.E. (2008): Is it too soon for mesenchymal stem cell trials in people with ALS? Amyotroph. Lateral Scler., Sept. 9, 321-322.

Balducci, M., Santoro, R., Mancini, G. and Balducci, D. (1962): Analysis of different cell systems for the production of attenuated poliomyelitis virus vaccine. Appl. Microbiol., 10, 190-192.

Dalbello-Haas, V., Florence, J.M. and Krivickas, L.S. (2008): Therapeutic exercise for people with amyotrophic lateral sclerosis or motor neuron disease. Cochrane Database Syst. Rev., CD005229.

Delzer, J., Hauser, H. and Lehmann, J. (1985): Production of human interferon-beta in mouse L-cells. Dev. Biol. Stand., 60, 413-419.

Ito, M., Hiramatsu, H., Kobayashi, K., Suzue, K., Kawahata, M., Hioki, K., Ueyama, Y., Koyanagi, Y., Sugamura, K., Tsuji, K., Heike, T. and Nakahata, T. (2002): NOD/SCID/gamma(c)(null) mouse: an excellent recipient mouse model for engraftment of human cells. Blood, 100, 3175-3182.

Ito, M., Kobayashi, K. and Nakahata, T. (2008): NOD/Shi-scid IL2rgamma(null) (NOG) mice more appropriate for humanized mouse models. Curr. Top. Microbiol. Immunol., 324, 53-76.

Koyanagi, Y., Tanaka, Y., Kira, J., Ito, M., Hioki, K., Misawa, N., Kawano, Y., Yamasaki, K., Tanaka, R., Suzuki, Y., Ueyama, Y., Terada, E., Tanaka, T., Miyasaka, M., Kobayashi, T., Kumazawa, Y. and Yamamoto, N. (1997): Primary human immunodeficiency virus type 1 viremia and central nervous system invasion in a novel hu-PBL-immunodeficient mouse strain. J. Virol., 71, 2417-2424.

Masters, J.R. (2002): HeLa cells 50 years on: the good, the bad and the ugly. Nat. Rev. Cancer, 2, 315-319.

Masuda, H., Maruyama, T., Hiratsu, E., Yamane, J., Iwanami, A., Nagashima, T., Ono, M., Miyoshi, H., Okano, H.J., Ito, M., Tamaoki, N., Nomura, T., Okano, H., Matsuzaki, Y. and Yoshimura, Y. (2007): Noninvasive and real-time assessment of reconstructed functional human endometrium in NOD/SCID/gamma c(null) immunodeficient mice. PNAS, 104, 1925-1930.

Matsuura-Sawada, R., Murakami, T., Ozawa, Y., Nabeshima, H., Akahira, J., Sato, Y., Koyanagi, Y., Ito, M., Terada, Y. and Okamura, K. (2005): Reproduction of menstrual changes in transplanted human endometrial tissue in immunodeficient mice. Hum. Reprod., 20, 1477-1484.

Moll, R., Franke, W.W., Schiller, D.L., Geiger, B. and Krepler, R. (1982): The catalog of human cytokeratins: patterns of expression in normal epithelia, tumors and cultured cells. Cell, 31, 1124.

Nakamura, M. and Suemizu, H. (2008): Novel metastasis models of human cancer in NOG mice. Curr. Top. Microbiol. Immunol.,
324, 167-177.

Ohbo, K., Suda, T., Hashiyama, M., Mantani, A., Ikebe, M., Miyakawa, K., Moriyama, M., Nakamura, M., Katsuki, M., Takahashi, K., Yamamura, K. and Sugamura, K. (1996): Modulation of hematopoiesis in mice with a truncated mutant of the interleukin-2 receptor gamma chain. Blood, 87, 956-967.

Okita, K., Ichisaka, T. and Yamanaka, S. (2007): Generation of germline-competent induced pluripotent stem cells. Nature, 448, 313-317.

Robinson, D.M., Berman, S., Lowenthal, J.P. and Hetrick, F.M. (1966): Western equine encephalomyelitis vaccine produced in chick embryo cell cultures. Appl. Microbiol., 14, 1011-1014.

Sambrook, J., Hanahan, D., Rodgers, L. and Gething, M.J. (1986): Expression of human tissue-type plasminogen activator from lytic viral vectors and in established cell lines. Mol. Biol. Med., 3, 459-481.

Suemizu, H., Monnai, M., Ohnishi, Y., Ito, M., Tamaoki, N. and Nakamura, M. (2007): Identification of a key molecular regulator of liver metastasis in human pancreatic carcinoma using a novel quantitative model of metastasis in NOD/SCID/gammacnull (NOG) mice. Int. J. Oncol., 31, 741-751.

Suemizu, H., Hasegawa, M., Kawai, K., Taniguchi, K., Monnai, M., Wakui, M., Suematsu, M., Ito, M., Peltz, G. and Nakamura, M. (2008): Establishment of a humanized model of liver using NOD/ Shi-scid IL2Rg(null) mice. Biochem. Biophys. Res. Commun., 377, 248-252.

Taghian, A., Budach, W., Zietman, A., Freeman, J., Gioioso, D., Ruka, W. and Suit, H.D. (1993): Quantitative comparison between the transplantability of human and murine tumors into the subcutaneous tissue of $\mathrm{NCr} / \mathrm{Sed}-\mathrm{nu} / \mathrm{nu}$ nude and severe combined immunodeficient mice. Cancer Res., 53, 5012-5017.

Takahashi, K., Tanabe, K., Ohnuki, M., Narita, M., Ichisaka, T., Tomoda, K. and Yamanaka, S. (2007): Induction of pluripotent stem cells from adult human fibroblasts by defined factors. Cell, 131, 861-872.

Yahata, T., Ando, K., Nakamura, Y., Ueyama, Y., Shimamura, K., Tamaoki, N., Kato, S. and Hotta, T. (2002): Functional human $\mathrm{T}$ lymphocyte development from cord blood CD34+ cells in nonobese diabetic/Shi-scid, IL-2 receptor gamma null mice. J. Immunol., 169, 204-209. 